\title{
Rethinking Scholastic Communities in Medieval Eurasia: Introduction
}

\section{Pascale Hugon and Birgit Kellner*}

The collection of five papers on scholastic communities in this issue emerged from a series of three consecutive workshops, conceived and organized within the framework of the Austrian Special Research Programme (SFB) »Visions of Community - Comparative Approaches to Ethnicity, Region and Empire in Christianity, Islam and Buddhism (400-1600 CE)« VISCOM for short (viscom.ac.at, 2011-2019). Pursuing the question of how universal religions shaped the construction of communities and identities in medieval times, VISCOM chiefly operated through selected historical-anthropological case studies in the Christian Latin West, Islamic South Arabia and Buddhist Tibet, which were integrated within a comparative research perspective. VISCOM connected three institutes at the Austrian Academy of Sciences - the Institutes for Medieval Studies (IMAFO), for Social Anthropology (ISA) and for the Cultural and Intellectual History of Asia (IKGA) -, as well as related institutes at the University of Vienna.

The VISCOM project placed special emphasis on visions of community and investigated the relationship between normative conceptions, developed within religions that exhibit a universalist aspiration, and localized historical processes and social practice. In an earlier phase of the VISCOM project, special communities and social structures devoted to scholarship and learning had been investigated under the umbrella of "Enclaves of Learning ${ }^{1}{ }^{1}$ Continuing this strand of enquiry, the workshop series "Rethinking Scholastic Communities Across Medieval Eurasia“ (2018-2019) turned its attention to the phenomenon whereby, in medieval times, specialized intellectual cultures developed and operated within environments shaped by the ideas and norms of universal religions, as well as by their practices and institutions.

In different ways, the category of scholasticism has informed comparative enterprises extending across Europe and Asia for a century already. In his 1920 article "La scolastique (étude de philosophie comparée)«, Paul Masson-Oursel spoke of scholasticism both as a "phase» in intellectual history and as a phenomenon with constitutive characteristics. He pointed out a set of three characteristics common to Western scholasticism - which included rationalistic currents within Christianity, Judaism and Islam - and what he terms the "oriental scholasticisms « of India and China: the use of commentaries to present one's ideas, the dialectical method and the high esteem for systematization. ${ }^{2}$ In an influential article published

\footnotetext{
* Correspondence details: Pascale Hugon and Birgit Kellner, Institute for the Cultural and Intellectual History of Asia, Austrian Academy of Sciences, Hollandstraße 11-13, 1020 Vienna, Austria; email: Pascale.Hugon@oeaw.ac.at, Birgit.Kellner@oeaw.ac.at.

1 See the relevant contributions in the mid-term volume Hovden et al., Meanings of Community.

2 Masson-Oursel, Scolastique, 133.
} 
in 1974, George Makdisi, arguing in favour of Islamic roots of medieval Christian scholasticism, characterized scholasticism as a method of presentation as well as a way of thinking. ${ }^{3}$ As a way of thinking, scholasticism is primarily concerned with the relationship between faith and understanding, driven by a deep and equal concern for authority and reason. Medieval Christian scholasticism is, in Makdisi's terms, a systematic exploration of faith resting on the premise that reason and revelation can be harmonized because both come from the same source; both were given to man by God. As a method of presentation, scholasticism is formal and systematic. It involves the application of a set of intellectual tools which serve the dual purpose of deepening the understanding of authoritative texts and doctrines, and of defending interpretations against real or hypothetical objections. The scholastic toolkit includes exegetical and hermeneutic, as well as dialectical or logical methods.

The potential of the concept of "scholasticism « for a comparative philosophy of religions was explored more thoroughly as well as with a broader perspective in the 1998 volume Scholasticism: Cross-Cultural and Comparative Perspectives edited by José Ignacio Cabezón, one of the contributors to this issue. The chapters in this volume dealt with scholasticism in relation to Christianity, Islam, Judaism, Daoism, Neo-Confucianism, Hinduism and Tibetan Buddhism. In the programmatic introduction, Cabezón eschewed a stipulative definition of scholasticism and pursued a strategy that has, in the meantime, become common currency in comparative cross-cultural enterprises: he resorted to a polythetic classification indicating common features exhibited in some combination in all forms of scholasticism, without necessarily being present together in all of them or in quite the same way. In other words, a set of features was introduced which allowed scholastic approaches to be recognized through Wittgensteinian family resemblances that make scholasticism a malleable category. ${ }^{4}$

Among these are a strong concern with tradition, transmission and language, as well as a commitment to systematicity and rationalism. As a particular approach within a larger religious framework, scholasticism tends towards proliferativity (to include rather than exclude), and towards completeness as well as compactness; scholastics aspire to overlook nothing essential and to include nothing inessential. Scholasticism also exhibits a self-reflexive dimension, insofar as scholastic authors analyse and codify the methods of reasoning which they apply in their works - hence the strong focus on logic and dialectics, i.e., rules and theories suitable for regulating scholarly exchange.

Generally in line with this endeavour, though not always explicitly based on precisely this set of features, scholars in the field of Asian Studies and of Buddhism in particular have come to favour scholasticism as an analytical, cross-cultural category, and engaged in comparison, especially with medieval scholasticism in the Latin West. Particularly prominent in this regard is Georges Dreyfus's The Sound of Two Hands Clapping (2003), an in-depth account of

4 These introductory considerations followed up on a previous work in which Cabezón applied the category of scholasticism in his exploration of classical Tibetan Buddhist philosophy in the Gelukpa ( $d G e$ lugs pa) school. See Cabezón, Buddhism and Language. For a critical discussion of Masson-Oursel and Cabezón's approaches, see now Eltschinger, From commentary to philosophy, 5-8. 
Tibetan Buddhist scholastic education informed by Dreyfus's own background as a former monk in the Gelukpa-school (dGe lugs pa). More recently, Vincent Eltschinger explored the potential of Indian Buddhism for comparative inquiries. ${ }^{5}$ Comparative studies of the Jewish, Christian, and Islamic scholastic traditions frequently focus on the question of their origin and direction of influence. ${ }^{6}$ By contrast, comparisons between the traditions of India or Tibet and Western scholasticism commonly rely on the premise that, while Tibet is heavily indebted to the sophisticated scholarly tradition of India, the Indian and Western traditions have emerged independently. An exception is found in Christopher Beckwith's comparison of the application, across medieval Eurasia, of specific argumentative structures which he terms the "true scholastic method ", which is tied to the (disputable) thesis of a historical influence of Indian scholasticism (via the Central Asian Sarvāstivāda school) on the Islamic world as well as on Tibet. ${ }^{7}$

While there is a long-standing perception of scholasticism as an arid intellectualism typical of European medieval schoolmen overcome by the dawn of the Renaissance, scholars in Asian Studies have rather striven to rehabilitate the category, viewing it as an avenue to do justice to the rich and variegated landscape of intellectual cultures within religious environments across Asia and the ways in which these cultures belong to the history of science and scholarship more broadly. Last but not least, they recognized it as having considerable potential for the comparative study of religion and philosophy in medieval environments. Against this background, it may not come as a surprise that within the VISCOM project, the initiative to introduce the category of scholasticism into the project's comparative horizon was taken by two scholars in Tibetan and Buddhist Studies who have both worked on the intellectual traditions of Indian and Tibetan Buddhism and, in particular, on the history of logic, Hugon and Kellner.

Resorting to the category of scholasticism in comparative endeavours is, however, not always perceived as unproblematic. Medievalists studying Latin Christianity are at times irritated when encountering the larger and perhaps bewildering ecosystem of cross-cultural studies on scholasticism, and on occasion have been known to insist that the category should indeed not be applied outside its prototypical point of reference: a period in the European history of philosophy defined by a predominance of "schools«. Yet, as Constant J. Mews suggests in his paper in this issue, this conception may in itself require reconsideration from

5 See Eltschinger, Qu'attendre d'une comparaison, and id., From commentary to philosophy.

6 See, for instance, Kohler, "Scholasticism«, on the claim of Jewish influence on Christian scholasticism; Becker, Comparative study of "scholasticism«, on Jewish and (oriental) Christian scholasticism; and Makdisi, Scholastic method, on the influence of Islamic scholasticism (itself shaped by Islamic law) on the scholastic method in Western Christianity, through channels such as Byzantium, Italy and Spain.

7 Beckwith, Sarvāstivādin Buddhist scholastic method. Beckwith defended the thesis of such an influence of Indian scholasticism already in his 1990 article, Medieval scholastic method, in which he also claims that the tripartite argumentative structure broadly used in Tibetan texts was an instance of the »true scholastic method.« He subsequently corrected the latter claim of an exact match (Sarvāstivādin Buddhist scholastic method, 171), but thereby (problematically) implicitly reduced »Tibetan scholasticism» to the presence of the "true scholastic method» in Tibetan translations of Indian works. 
a historical point of view. Moreover, if one grants that there is plenty of evidence for the existence of specific modes of specialized learning and thinking that developed within a number of religious traditions, surely something can be gained by considering individual manifestations of this phenomenon in critical comparison - and by considering medieval scholasticism in Europe not as a stage within a teleological model of history that is problematic in and of itself, but simply as one manifestation of a larger cross-cultural phenomenon. One would run the risk of simply missing out on specialized intellectual cultures as a global phenomenon - not to mention on possible hitherto overlooked historical connections - if one were to eschew the category of scholasticism and resorted to even broader comparisons framed in terms of "intellectual cultures" or "scholarly cultures in religious contexts".

A second critical issue that is often raised is that even within the Western medieval context, the category of scholasticism is problematic insofar as it artificially homogenizes different methodologies and communities at work while blocking the path to recognizing their distinctive characteristics. This issue, in fact, similarly applies to the now widespread and somewhat indiscriminate use of the term in Indian and Tibetan Studies. To exemplify the problem for the Tibetan case, the Gelukpa school stemming from Tsongkhapa (Tsong kha pa, 1357-1419) used to be taken as a paradigm for scholasticism, but as the study of Tibetan Buddhist literature advanced over the past decades, it has become increasingly obvious that other Tibetan Buddhist schools and lineages, in particular the Sakyapa ( $S a$ skya pa), also exhibit strong scholastic characteristics. ${ }^{8}$ Some scholars reserve the epithet "scholastic " for what they consider a post-classical period of the sixteenth to the nineteenth century, ${ }^{9}$ or consider this period to be the most representative of Tibetan scholasticism. ${ }^{10}$ This is expected to become an even more critical issue now that a large corpus of literature belonging to the formative phase of Tibetan traditions of learning in the eleventh-thirteenth centuries is gradually being studied, a phase which has been termed "early Tibetan scholasticism «. ${ }^{11}$ In the context of Indian Studies, there is a broad range of phenomena and traditions for which modern scholars use the label "scholastic «. ${ }^{12}$ Besides some delineating uses of this label for instance in Buddhist Studies, to refer to certain intellectual cultures and traditions that flourished in monastic contexts, most notably the doctrinal, exegetical and philosophical current called Abhidharma ${ }^{13}$ - there is a tendency to apply the term interchangeably with "scholarly" or "philosophical« to highlight intellectualist movements within religions as opposed to, say, currents that emphasize ritual or meditation. This not only broadens the denotation of "scholastic " to a questionable point, but also arguably imposes an overly rigid framework on historical and social realities.

11 For an introduction, see Hugon and Vose, Unearthing the foundations.

12 See, for instance, the forthcoming volume edited by Colas and Aussant, Scolastiques indiennes.

13 See, among others, Dessein et al., Sarvästivāda Buddhist Scholasticism, as well as Cox's earlier and particularly thorough article: Unbroken treatise. 
The papers in this issue address these and similar problems involved with the category of scholasticism and its application to different historical, social and cultural settings. In different ways, they show that the very engagement with these problems - and perhaps even the resistance to using the very category - lends it a critical edge as a heuristic notion in comparative endeavours, and might, in the end, even make it more productive for comparative discourse than more general and uncontroversial categories such as "cultures of learning." But more importantly, taking as their point of departure the notion of scholastic communities, the papers in this issue adopt a more strongly pronounced sociohistorical perspective. Scholasticism has often been characterized in terms of a method, involving, e.g., the use of distinctions and definitions, a scheme of disputation, ${ }^{14}$ or it has been considered even more strictly from the angle of its dialectical method alone. However, explorations exclusively oriented on the axis of method risk overemphasizing formal commonalities when performed from within a comparative approach that too strongly abstracts both from the specific theoretical contexts in which these methods were employed and from the social environments in which they were used; Beckwith's abovementioned study is disputable on this ground, as well. Accordingly, we concur with Eltschinger when he highlights the significance of structures rather than only ideas or methods. He further argues for "a comparative approach to knowledge-producing intellectual cultures rather than dogmas, doctrines and arguments «. ${ }^{15}$ For Eltschinger, the priority for investigation in the comparative study of scholasticisms would then be "the institutional environment, the teaching and scholarly practices, the many ways in which knowledge was produced, stored, enriched and made to fructify, etc. ${ }^{16}$ Here, however, one might raise the question whether institutional and social aspects of knowledge production can really be considered in isolation from the content of what was taught, and theoretical aspects pertaining to the history of ideas. Approaching religious traditions in medieval Eurasia through the lens of "scholastic communities « thus offers a framework for exploring intellectual orientations within the context of religions and how the specialized knowledge which they produced contributed to community building. These two aspects have the potential to cast a fresh light on the nature of religious communities at large, and on the notion of »learning " as a category that can be historicized.

The workshop series "Rethinking Scholastic Communities across Medieval Eurasia« consisted of three one-day workshops spread across 2018 and 2019. The series made use of the already established research environment of VISCOM to bring social and historical aspects into the foreground, but at the same time, strove not to neglect the textual and intellectual dimensions of scholastic enterprises at their expense. Each of the three one-day workshops was planned to explore a particular theme through papers on the three core regions and

14 From Grabmann, in his 1909 Geschichte der scholastischen Methode, to, e.g., De Rijk, in his 1985 Philosophie au moyen âge.

15 Eltschinger, Qu'attendre d'une comparaison, 123. See also ibid., 126-127. In this publication the author surveys the questions of the institutional framework, authority, organization of knowledge, commentaries, rationality (including argumentation and debate) and language.

16 Eltschinger, From commentary to philosophy, 275. 
religions of the VISCOM project, and to foster intense discussion between invited speakers, members of the VISCOM team and associated scholars and students in Vienna. The workshops were designed to stimulate a continuous process of discussion across a multifarious assembly of participants, as contributions by the speakers and discussants of the previous workshops were made available to those of the subsequent events well in advance. Minutes of the discussions were taken and also made available to all participants, enabling them to integrate the collective discussion process while revising their papers for publication.

The first workshop, held on 27th March 2018, tackled the topic of »Scholastic Communities" as such, and served to introduce general questions and sketch general contours of investigation; the papers by Constant J. Mews and José Ignacio Cabezón result from presentations given at this particular event. Unfortunately, the renowned scholar of Islamic history Wilferd Madelung, whom we had invited to cover South Arabian Islam, had to cancel his participation for personal reasons. The second and third workshops, held on 24th October 2018 and 27th March 2019, built upon these more general reflections and focused on "Authority and Authorship" and "Intellectual Methods and Practices" respectively. An earlier version of Cathy Cantwell's paper from this issue was presented at the second workshop. Hassan Ansari (Princeton University) presented an excellent paper on »Imam al-Manșūr bi-llāh 'Abdullāh b. Hamza: A Zaydī ruler and author « that enriched the discussion considerably, but Ansari regrettably decided not to submit his presentation for publication. Similarly, Sita Steckel (University of Münster) was unfortunately unable to submit her succinct presentation "Masters, exegetes, theologians: Authority and authorship in northwestern European schools c. 10501150«. The papers by Bénédicte Sère and Jonathan Samuels in this issue were presented at the third workshop, dealing with intellectual methods and practices. Jan Thiele (Centre for Human and Social Sciences, Spanish National Research Council) also spoke on »The rise of a scholastic community: Zaydi theology in twelfth-century Yemen «. Thiele, too, was unable to revise his paper for publication. This unfortunate coincidence leaves us in the uncomfortable situation that the substantial contributions made to the workshop through the consideration of Islam in South Arabia are not expressly represented in this issue, even though it undoubtedly - and positively - influenced the horizon of the published papers in more indirect ways.

The role of the chairpersons and discussants is a particularly significant one in such an interactive process. We therefore thank the chairpersons Andre Gingrich (ISA), Christina Lutter (University of Vienna), Diarmuid O'Riain (IMAFO) and Johann Heiss (ISA), as well as the discussants Sita Steckel (University of Münster), Florian Schwarz (Institute of Iranian Studies [IFI], Austrian Academy of Sciences), Rutger Kramer (IMAFO), Christophe Erismann (University of Vienna) and Markus Viehbeck (University of Vienna). Hugon and Kellner also acted as chairperson and discussant respectively. Sophie Gruber (IMAFO) and Cynthia PeckKubaczek (IKGA) offered invaluable help in organizing the workshop series. Reinier Langelaar (IKGA) is to be thanked for taking the minutes of the discussions that followed each presentation, and for providing participants of the following workshop with a remarkably clear and succinct account of the state of discussion.

The five papers in this issue are rooted in the specific historical and cultural expertise of medievalists focusing on the Latin West and scholars of Tibetan Buddhism. While making original contributions in their own respective fields, they are also informed by the comparative horizon that framed the entire workshop series. The paper by José Ignacio Cabezón rethinks Buddhist scholastic communities through a sociohistorical lens, building upon Cabezón's earlier, more synchronic and structuralist work. To understand Tibetan Buddhist scholasti- 
cism better, Cabezón goes back to the Indian Buddhist tradition and reflects on the general conditions for the formation of Buddhist scholastic communities in ancient India: the development of sedentary monastic communities, the adoption and cultivation of writing as a cultural technique, and exchange - in the form of written and oral debate, in a strongly regularized format - with rival schools, especially ones from the Brahmanical fold. Expanding the sphere of consideration to encompass later Tibetan developments, Cabezón then addresses three particular characteristics of mature Buddhist scholasticism: debate, the oscillation of the commentarial corpus between expansion and contraction, and the role of prayer and ritual in scholastic learning, the last of which is particularly significant for the existence of scholarly communities as religious institutions. Concluding reflections touch upon internal (ideological) as well as external (political) challenges faced by scholastic communities.

While Cabezón demonstrates how a reconsideration of scholasticism as a cross-cultural category from a sociohistorical perspective can be productive, Constant J. Mews draws attention to problems resulting from an approach that defines scholasticism through a certain view of its role in the medieval Latin West from where the category came to be borrowed: the idea of scholasticism as a stable and rather uniform system involving, as Makdisi would have it, the reconciliation of faith and reason. By turning to the twelfth rather than the thirteenth century in Europe, Mews argues that historical analysis must pay greater attention to competitions between masters and their various schools, as well as their distinctive ways of responding to voices and texts from outside the Latin West. Based on a wide range of considerations, Mews concludes that the notion of monasticism and scholasticism as competing perspectives stands in the way of a historically nuanced picture that manages to accommodate this diversity of theological positions, as well as the diffusion of scholastic texts in monastic milieus.

Cathy Cantwell's contribution similarly questions the category of scholasticism on the basis of new historical research, in her case on the seminal figure of Nyangrel Nyima Özer (Myang ral Nyi ma 'od zer, 1124-1192), a foundational figure in the early history of the Tibetan Buddhist school of the Nyingmapa ( $r$ Nying $m a$ pa), i.e., the "Ancients«. Both the Nyingmapa school and Nyangrel might initially be viewed as the "other " of Tibetan scholasticism. Nyangrel and his successors made no attempt at forming a social entity akin to a monastic order that would have accommodated colleges. As visionaries operating in family-based hereditary lineages, they did not place emphasis on practices like disputation. Neither did most Nyingmapa scholars focus on logic or other forms of rational analysis germane to scholastic communities. An exception in this regard in the Nyingmapa school would be the eleventh-century scholar Rongzom Chökyizangpo (Rong zom Chos kyi bzang po). Yet, based on her recent research on the large textual corpus "revealed « by Nyangrel - with the notion of scriptural revelation posing significant challenges to notions of authorship -, Cantwell argues that in this early period, where scholastic colleges in the other schools were yet to emerge, one can, in fact, argue for significant overlap across communities that only later become more sharply divided into different types of schools. This overlap concerns especially processes of gathering, editing and systematizing textual heritage recovered from various sources. The suggestive conclusion is that perhaps later forms of Tibetan Buddhist scholasticism should historically be approached as emerging from a much broader earlier sociocultural matrix than was hitherto taken into consideration.

Turning to intellectual methods and practices, both Jonathan Samuels and Bénédicte Sère focus on disputation - or debate - as a central element of scholastic communities, in Tibet (Samuels) and in the Latin West (Sère) respectively. Sère considers medieval disputation in Europe as a means for producing knowledge, doctrine or theory. Distinguishing a Haberma- 
sian »irenic disputation from a Bourdieu-inspired "polemical« counterpart, she first outlines the contours of medieval disputation in general and then discusses specific cases to illustrate each category. Her discussion of the broader range of polemics leads her to explore the social boundaries of the scholastic - academic - realm. In a paper that couples historical enquiry with methodological reflection, Samuels argues in favour of reading even the highly theoretical and normative treatises that make up the source record for Tibetan Buddhist scholasticism from a sociohistorical vantage point, focusing on what Samuels refers to as "the language«. This, he argues, can support hypotheses about institutional dynamics even in the often-lamented absence of historical records that might offer more concrete evidence for them. Disputation is strongly linked, if not exclusively concentrated on, the proper understanding and interpretation of Buddhist doctrine and philosophy; this appears to have been marked as its territory from early on. Samuels offers a counter-model to the narrative that currently dominates in Tibetological scholarship, according to which the Gelukpa school stands for a sterile formalization of much livelier earlier practice. He argues that this narrative conflates the domains of historical practice and scholastic literature, and posits historical practice as the primary target of research, exemplifying this with a rare instance of a record of disputation from the fourteenth century. Instead, he highlights institutions as providing incentives and structures for debate, and argues that what was often at stake in debate practice is less its explicit content, but rather the institution itself. From a comparative perspective, he points out several divergences between Tibetan disputation and debate in medieval European universities. His rich paper deepens reflections on the medieval period by expanding the scope to include post-medieval developments, as well as conclusions drawn from Samuel's own first-hand experience in contemporary disputation practice (chiefly in the Gelukpa tradition). It serves as a reminder that comparison thrives on attending to differences premised on a recognition of shared basic features.

The discussions carried out at the three workshops highlighted a number of additional areas of exploration that may help to stimulate future research along the lines suggested in the five papers on these issues. A first suggestion made was to change perspective altogether and view scholastic practices such as commentary or disputation as part of religious experience or practice. This would allow linking them with other significant practices in either context, most notably meditation, prayer and ritual. Especially as far as prayer and ritual is concerned, this would also place a new focus on the communal aspects of religious practice in medieval times, and perhaps even lead to recognizing communal dimensions of contemplative practices that, rightly or wrongly, tend to be approached as being of a solitary nature. Secondly, the focus on scholastic communities also highlighted problems in drawing distinctions between "lay" and "religious « communities. These problems become especially evident when one considers the relationship between scholastic communities and educational structures in the respective historical settings: strong personal teacher-student bonds in Indian and Tibetan Buddhism, for instance, might work within, but also outside monasteries as educational institutions. Literacy, its extent and its relationship to oral teaching practices, was raised as an additional topic to be considered when it comes to the ways in which scholastic communities operate in their larger social environment, but also when it comes to the circulation of scholastic literature. Gender seems an obvious further area of enquiry, in the Tibetan case insofar as scholastic communities were typically groups of celibate male religious specialists (monks). Lastly, the relationship between scholastic literature and fields of learning or scholarship more broadly (but particularly with legal and medical fields) was also raised. 
The serial workshop and the papers that resulted have been a further step in integrating non-European cultures into a "global history of scholasticism«. They testify to the benefit of pursuing these investigations in a comparative perspective, a perspective that will continue gaining in refinement with the consideration of an expanding pool of cultures and particular traditions. 


\section{References}

Becker, Adam H., The comparative study of "scholasticism « in late antique Mesopotamia: Rabbis and East Syrians, AJS Review 34/1 (2010) 91-113.

Beckwith, Christopher, The medieval scholastic method in Tibet and the West, in: Lawrence Epstein and Richard F. Sherburne (eds.), Reflections on Tibetan Culture: Essays in Memory of Turrell V. Wylie (Lewiston, 1990) 307-313.

Beckwith, Christopher, The Sarvāstivādin Buddhist scholastic method in medieval Islam and Tibet, in: Anna Akasoy, Charles Burnett and Ronit Yoeli-Tlalim (eds.), Islam and Tibet Interactions along the Musk Routes (Farnham, 2011) 163-175.

Cabezón, José Ignacio, Buddhism and Language: A Study of Indo-Tibetan Scholasticism (Albany, 1994).

Cabezón, José Ignacio (ed.), Scholasticism: Cross-cultural and Comparative Perspectives (Albany, 1998).

Colas, Gérard and Émilie Aussant, Les scolastiques indiennes: Naissances, développements, interactions (Paris, forthcoming).

Cox, Collett, The unbroken treatise: Scripture and argument in early Buddhist scholasticism, in: Michael Williams and Collett Cox (eds.), Innovation in Religious Traditions (Berlin, 1992) 143-189.

Dessein, Bart, Charles Willemen and Collett Cox (eds.), Sarvāstivāda Buddhist Scholasticism (Leiden, 1998).

Dreyfus, Georges, The Sound of Two Hands Clapping (Berkeley, 2003).

Eltschinger, Vincent, From commentary to philosophy, or lectio and disputatio in Indian Buddhist commentarial literature, in: Silvia D'Intino and Sheldon Pollock (eds.), The Space of Meaning: Approaches to Indian Philology (Paris, 2018) 271-303.

Eltschinger, Vincent, Qu'attendre d'une comparaison des scolastiques? Buddhisme indien et Occident médiéval, Socio-anthropologie 36 (2017) 123-142.

Grabmann, Martin, Die Geschichte der scholastischen Methode (Freiburg im Breisgau, 1909).

Hovden, Eirik, Christina Lutter and Walter Pohl (eds.), Meanings of Community across Medieval Eurasia (Leiden, 2016).

Hugon, Pascale and Kevin Vose, Unearthing the foundations of Tibetan Buddhist philosophy, Journal of the International Association of Buddhist Studies 32/1-2 (2010) 237-248.

Kapstein, Matthew T., What is »Tibetan scholasticism «? Three ways of thought, in: Matthew T. Kapstein, The Tibetan Assimilation of Buddhism: Conversion, Contestation, and Memory (Oxford, 2000) 85-120.

Kohler, George, "Scholasticism is a daughter of Judaism «: The discovery of Jewish influence on medieval Christian thought, Journal of the History of Ideas 78 (2017) 319-340.

Makdisi, Georges, The scholastic method in medieval education: An inquiry into its origins in law and theology, Speculum 49 (1974) 640-661.

Masson-Oursel, Paul, La Scolastique (étude de philosophie comparée), Revue Philosophique de la France et de l'Étranger 90 (1920) 123-141.

De Rijk, Lambertus Marie, La philosophie au moyen âge (Leiden, 1985).

Ruegg, David Seyfort, Three Studies in the History of Indian and Tibetan Madhyamaka Philosophy (Vienna, 2000). 